\title{
Is Quantitative sIgE Serology Suitable for Distinguishing Between Silent Sensitization and Allergic Rhinitis to Dermatophagoides pteronyssinus?
}

\author{
Gellrich D'1, Högerle $\mathrm{C}^{1}$, Becker S², Gröger $\mathrm{M}^{1}$ \\ 'Department of Otorhinolaryngology, Head and Neck Surgery, Ludwig-Maximilians-University Hospital, Munich, Germany \\ ${ }^{2}$ Department of Otorhinolaryngology, Head and Neck Surgery, University Medical Center, Johannes Gutenberg-University, Mainz, Germany
}

J Investig Allergol Clin Immunol 2019; Vol. 29(2): 124-131

doi: 10.18176/jiaci.0299

\begin{abstract}
Background: An increasing number of studies have recently discussed whether provocation tests might be replaced by specific lgE serology in patients sensitized to airborne allergens.

Objective: Our study aimed to analyze the concordance between a nasal provocation test with Dermatophagoides pteronyssinus and specific lgE measurements based on real-life data.

Patients and Methods: We retrospectively analyzed concordance between the result of the provocation test and the lgE titer for house dust mite components and extracts in 223 patients with proven sensitization to $D$ pteronyssinus.

Results: In contrast to findings from other studies, the anti-Der 11 level alone was not sufficient to distinguish between silent sensitization and allergy to D pteronyssinus. ROC curve analysis revealed that the sum of slgE against Der $p 1$ and Der $p 2$ is - after adjustment for total serum IgE-the best parameter for discriminating between clinically silent and relevant sensitization. However, it does not have sufficient validity to confirm a diagnosis.

Conclusions: Despite the high correlation between slgE levels and symptoms, no serologic parameter is sufficiently accurate to distinguish between silent sensitization and clinically relevant allergy. Therefore, nasal provocation tests remain the gold standard for assessing clinical relevance in sensitization to $D$ pteronyssinus.
\end{abstract}

Key words: Correlation. IgE serology. Nasal provocation test. Allergy. Sensitization. House dust mite.

\section{Resumen}

Introducción: Recientemente, un número cada vez mayor de estudios se han centrado en el debate sobre si las pruebas de provocación podrían ser reemplazables por medición de lgE específica en suero en pacientes sensibilizados a aeroalérgenos.

Objetivo: Nuestro estudio tuvo como objetivo analizar la concordancia entre la prueba de provocación nasal con Dermatophagoides pteronyssinus y la lgE específica con datos de vida real.

Pacientes y métodos: En 223 pacientes con sensibilización probada a Dermatophagoides pteronyssinus, se analizó retrospectivamente la concordancia entre el resultado de la prueba de provocación y el título de lgE frente a varios componentes y extractos de ácaros del polvo doméstico.

Resultados: A diferencia de otros estudios, el nivel de anti-Der $p 1$ no fue adecuado para distinguir entre una sensibilización silente y la alergia a Dermatophagoides pteronyssinus. El análisis de las curvas ROC reveló que la suma de slgE frente a Der p 1 y Der p 2, después del ajuste a la lgE sérica total, es el mejor parámetro para discriminar entre sensibilización clínicamente silente y relevante, aunque lejos de alcanzar una suficiente validez diagnóstica.

Conclusiones: A pesar de la alta correlación entre los niveles de slgE y los síntomas, ningún parámetro serológico tenía una precisión suficientemente alta para distinguir entre la sensibilización silente y una alergia clínicamente relevante. Por lo tanto, las pruebas de provocación nasal siguen siendo el patrón estándar para investigar la relevancia clínica de la sensibilización a Dermatophagoides pteronyssinus.

Palabras clave: Correlación. IgE en suero. Provocación nasal. Alergia. Sensibilización. Ácaros del polvo. 


\section{Introduction}

House dust mite (HDM) is the third most relevant allergen in many countries, following grass and birch pollen [1]. The clinical and socioeconomic impact of allergy to HDM is considerable, given that untreated disease carries an increased risk of developing asthma [2-4]. Consequently, correct diagnosis of assumed HDM allergy is crucial in order to initiate appropriate treatment to prevent development of asthma. However, as the clinical history is not always reliable regarding HDM allergy [5], the condition could prove difficult to diagnose, especially given the lack of seasonal symptoms. Skin prick test (SPT) and the determination of allergen-specific $\operatorname{IgE}(\mathrm{sIgE})$ are the main approaches for testing patients suspected of having HDM allergy [6]. However, both tests detect sensitization, which is not always equivalent to a clinically relevant allergy. Allergen provocation testing is necessary to determine the clinical relevance of sensitization. In allergic rhinitis, this approach takes the form of nasal allergen challenge $[7,8]$, which is time-consuming. Consequently, many doctors avoid nasal provocation testing (NPT).

Oral food challenge, which is the gold standard for diagnosing hypersensitivity to food, is even more troublesome for patients and their doctors [9]. Therefore, health professionals try to reduce the need for challenge tests in food allergy. In recent years, the question of whether in vivo challenges might be replaced by less risky in vitro tests is increasingly debated with regard to airborne allergens [10].

The trend from in vivo diagnostics of IgE-mediated allergies toward in vitro diagnostics might be due to the progress made in component-resolved diagnostics. Furthermore, increased regulatory demands in the EU make in vitro testing more likely [11]. The diagnostic test allergens used in the EU have to be authorized for each test method in each EU member state. Consequently, allergen-specific in vivo tests are less available. In vitro assays cannot completely match the diagnostic value of in vivo tests [12].

An increasing number of publications address the question of whether sIgE measurements might help to distinguish between clinically silent sensitization and symptomatic allergy. Whereas earlier studies primarily used allergen extracts $[13,14]$, recent studies are mainly performed with recombinant allergen components $[10,15]$. Two recent publications even indicated that measurement of specific IgE to Der p 1 might consign HDM challenge tests to history $[15,16]$. Our study aimed to analyze real-life data to determine whether NPT with Dermatophagoides pteronyssinus is replaceable by sIgE measurements. In our department, all patients suspected of having allergic rhinitis undergo SPT with $D$ pteronyssinus, which is the main species of HDM in Germany. Additionally, all patients with a positive SPT result to HDM and/or a clear clinical history undergo tests based on reactivity of $\operatorname{sgE}$ to natural HDM extract and the allergens Der p 1 and Der p 2. Furthermore, all patients sensitized to HDM undergo NPT. Consequently, we have access to a large number of patients sensitized to D pteronyssinus with well-known SPT results, sIgE measurements, and NPT results. Analysis of our large and representative patient database enabled us to investigate whether determination of sIgE make it possible to distinguish between clinically silent sensitization and relevant allergy to $D$ pteronyssinus.

\section{Patients and Methods}

\section{Study Population}

Patient data were retrospectively retrieved from the allergy database of the Department of Otorhinolaryngology of Ludwig-Maximilians-University, Munich, Germany.

The database was scanned to identify patients with proven sensitization to HDM based on a positive SPT result or a positive sIgE measurement. All patients underwent SPT and allergen-specific provocation as routine in vivo tests and total $\operatorname{IgE}$ and allergen-specific $\operatorname{IgE}$ measurements in serum as in vitro tests. The database includes data from a standardized clinical history questionnaire covering seasonal complaints, demographic data, home environment, oral allergy syndrome, and medical history. Of 241 patients with positive SPT results to HDM, 9 patients were excluded as false positives because of negative IgE measurements.

The study was based on anonymized data and approved by the local ethics committee. All patients provided their written informed consent for the use of their data for scientific purposes.

\section{Fluorescence Enzyme Immunoassay}

IgE reactivity to natural allergen extract (d1) and allergen components Der p 1 and Der p 2 was measured using fluorescence enzyme immunoassay (UniCAP-FEIA, Thermo Fisher Scientific) with a commercially available test kit (Phadia Diagnostics). In the case of a positive SPT result to allergens other than HDM, specific IgE antibodies to the corresponding native extracts and allergen components were also measured. Results were reported as concentrations (kU/L).

\section{Skin Prick Testing}

SPT was performed with a solution for HDM from ALK-Abelló. The procedure was in line with published guidelines [17].

\section{Nasal Provocation Testing}

All patients sensitized to HDM underwent NPT in accordance with current guidelines [18]. The protocol included active anterior rhinomanometry (RhinoSys, Happersberger otopront $\mathrm{GmbH}$ ) to obtain a baseline measurement after the administration of allergen-free solution (LETI Pharma GmbH) and finally after the application of solution containing the allergen (D pteronyssinus, $100 \mathrm{HEP} / \mathrm{mL}$; LETI Pharma GmbH) through a nasal spray pump. Additionally, patients reported their symptoms so that a symptom score could be calculated.

The intranasal challenge was rated positive for patients who showed either a decrease in airflow of $>40 \%$ at $150 \mathrm{~Pa}$ on the allergen-challenged side, a symptom score of $>3$, or a combination of a symptom score of $>2$ and a reduction 
Table 1. Demographic and Clinical Data of Patients Allergic to Dermatophagoides pteronyssinus and Patients With Clinically Silent Sensitization to D pteronyssinus

\begin{tabular}{|c|c|c|c|}
\hline Characteristics & Positive NPT (n=160) & Negative NPT $(\mathrm{n}=72)$ & Total $(\mathrm{N}=232)$ \\
\hline \multicolumn{4}{|l|}{ Gender } \\
\hline Male & $98(61 \%)$ & $42(58 \%)$ & $140(60 \%)$ \\
\hline Female & $62(39 \%)$ & $30(42 \%)$ & $92(40 \%)$ \\
\hline Age, y & 29 (range, 18-39) & 30 (range, 18-48) & 29 (range, 17-41) \\
\hline Monosensitized to HDM & $35(22 \%)$ & $13(18 \%)$ & $48(21 \%)$ \\
\hline Oligosensitized (to 2-4 allergens) & $65(40 \%)$ & $37(51 \%)$ & $102(44 \%)$ \\
\hline Polysensitized (to $\geq 5$ allergens) & $60(38 \%)$ & $22(31 \%)$ & $82(35 \%)$ \\
\hline \multicolumn{4}{|l|}{ Cosensitization against } \\
\hline Grass & $101(63 \%)$ & $46(64 \%)$ & $147(63 \%)$ \\
\hline Birch tree & $77(48 \%)$ & $37(51 \%)$ & $114(49 \%)$ \\
\hline Ash tree & $89(56 \%)$ & $30(42 \%)$ & $119(51 \%)$ \\
\hline Mugwort & $33(21 \%)$ & $11(15 \%)$ & $44(19 \%)$ \\
\hline Cat & $60(38 \%)$ & $31(43 \%)$ & $91(39 \%)$ \\
\hline Asthmatic complaints & $48(30 \%)$ & $31(43 \%)$ & $79(34 \%)$ \\
\hline \multicolumn{4}{|c|}{ Severity of rhinitis (according to ARIA criteria) } \\
\hline Not known & $50(31 \%)$ & $5(7 \%)$ & $55(24 \%)$ \\
\hline Known & $110(69 \%)$ & $67(93 \%)$ & $177(76 \%)$ \\
\hline Intermittent mild & $12(11 \%)$ & $10(15 \%)$ & $22(12 \%)$ \\
\hline Intermittent moderate-severe & $23(21 \%)$ & $18(27 \%)$ & $41(23 \%)$ \\
\hline Persistent mild & $11(10 \%)$ & $10(15 \%)$ & $21(12 \%)$ \\
\hline Persistent moderate-severe & $64(58 \%)$ & $29(43 \%)$ & $93(53 \%)$ \\
\hline
\end{tabular}

Abbreviations: ARIA, Allergic Rhinitis and its Impact on Asthma; HDM, house dust mite; NPT, nasal provocation test.

aExcept for the rate of self-reported asthma which was higher in patients with negative nasal provocation test, the clinical and demographic data were comparable in both groups.

in airflow of $>20 \%$. Secretion, irritation, and remote symptoms were semiquantitatively assessed to determine the symptom score. In the case of a negative NPT result despite strong evidence in the history in favor of a clinically relevant HDM allergy, NPT was repeated with a different provocation test solution (Allergopharma $\mathrm{GmbH}$ ). In the case of doubtful results, a conjunctival provocation test was performed. The test involved instillation of $25 \mu \mathrm{L}$ of allergen-free test solution in the inferior-external quadrant of the bulbar conjunctiva of one eye and the same volume of test solution containing $D$ pteronyssinus in the bulbar conjunctiva of the other eye. After 10 minutes, the response was evaluated by a clinical assessment of itching, redness, tearing, and chemosis.

\section{Statistical Analysis}

The statistical analysis was performed with SPSS 18.0 (SPSS Inc). All of the data failed normality testing. For descriptive statistics, we used median values and the range. The Mann-Whitney test was used to compare the different groups. A value of $P \leq .05$ was considered significant.

We also analyzed the receiver operating characteristics (ROC) curve and calculated the area under the curve (AUC), which represented the statistical accuracy of $\operatorname{sIgE}$ as a diagnostic method for distinguishing between clinically silent sensitization and symptomatic allergy. Proportions were compared using the $\chi_{2}$ test.

\section{Results}

Based on the above-mentioned inclusion criteria, the database yielded 232 patients with proven sensitization to D pteronyssinus. Sensitization was considered proven in cases of positive sIgE reactivity against the natural HDM extract (d1). Table 1 summarizes the demographic and clinical data of the study population, which was divided into 2 groups: 160 patients with a positive NPT result to $D$ pteronyssinus and 72 patients with a negative NPT result to $D$ pteronyssinus. Males were slightly predominant in both groups (average $60 \%$ male). Median age was comparable in both groups. Furthermore, the distribution of monosensitization (IgE to a single allergen source), oligosensitization (IgE to 2-4 allergen sources), and polysensitization (IgE to $>4$ allerg en sources) was similar in both groups, even with similar cosensitization rates (Table 1 ).

We found that $34 \%$ of all patients sensitized to $D$ pteronyssinus had asthma confirmed by lung function tests including the methacholine challenge test; however, the prevalence for asthma was higher in patients with silent sensitization than in patients with $D$ pteronyssinus-related allergic rhinitis (43\% vs 30\%). The degree of sensitization was high, with $47 \%$ of asthma patients being polysensitized. In contrast, only $28 \%$ of D pteronyssinus-sensitized patients without asthma were polysensitized.

Laboratory data are shown in Table 2. Further discrepancies were found between allergic patients and patients with 
Table 2. Laboratory Characteristics of Patients Allergic to Dermatophagoides pteronyssinus Compared With Patients With Clinically Silent Sensitization to $D$ pteronyssinus

\begin{tabular}{|c|c|c|}
\hline Laboratory Characteristics ${ }^{\mathrm{b}}$ & Positive NPT $(\mathrm{n}=160)$ & Negative NPT $(n=72)$ \\
\hline Total IgE, kU/L & 148 (range, 60-294) & 187 (range, 88-408) \\
\hline $\begin{array}{l}\text { Natural extract d } 1 \\
\text { CAP class } \\
\text { Serum IgE level, kU/L } \\
\text { Quotient sIgE/total IgE }\end{array}$ & $\begin{array}{c}160(100 \%) \\
3(\text { range }, 2-3.25) \\
7.33 \text { (range, } 2.33-17.6) \\
0.056 \text { (range, } 0.021-0.13)\end{array}$ & $\begin{array}{c}72(100 \%) \\
2(\text { range, } 2-3) \\
2.07 \text { (range, } 1.05-9.35) \\
0.0157 \text { (range, } 0.008-0.051)\end{array}$ \\
\hline $\begin{array}{l}\text { Der } \mathrm{p} 1+ \\
\text { CAP class } \\
\text { Serum IgE level, kU/L } \\
\text { Quotient sIgE/total IgE }\end{array}$ & $\begin{array}{c}112(70 \%) \\
3(\text { range }, 2-3) \\
4.91 \text { (range, } 1.65-15.1) \\
0.016 \text { (range, } 0.0019-0.06)\end{array}$ & $\begin{array}{c}31(43 \%) \\
3(\text { range, } 2-3) \\
3.86 \text { (range, } 1.43-13.8) \\
0.001 \text { (range, } 0.0002-0.02)\end{array}$ \\
\hline $\begin{array}{l}\text { Der p } 2+ \\
\text { CAP class } \\
\text { Serum IgE level, kU/L } \\
\text { Quotient sIgE/total IgE }\end{array}$ & $\begin{array}{c}133(83 \%) \\
3(\text { range, } 2.75-4) \\
8.55(\text { range, } 3.56-18.9) \\
0.04(\text { range, } 0.003-0.1)\end{array}$ & $\begin{array}{c}40(56 \%) \\
2.5(\text { range }, 2-3) \\
4(\text { range, } 1.41-12.5) \\
0.0047(\text { range, } 0-0.031)\end{array}$ \\
\hline $\begin{array}{l}(\text { Der } \mathrm{p} 1+2)>0 \\
\text { Sum serum IgE level, kU/L } \\
\text { Quotient sIgE/total IgE }\end{array}$ & $\begin{array}{c}134(84 \%) \\
12.23(\text { range, } 4.73-32.95) \\
0.103 \text { (range, } 0.038-0.205)\end{array}$ & $\begin{array}{c}49(68 \%) \\
4.65 \text { (range, } 1.64-17.15) \\
0.039 \text { (range, } 0.011-0.137)\end{array}$ \\
\hline
\end{tabular}

Abbreviation: NPT, nasal provocation test.

aDespite a higher total lgE level, patients with negative nasal provocation test results had lower titers of slgE against Der $p 1$ and Der $p 2$. As shown in the lowest section of the table, $21 \%$ of all cases did not show any slgE against Der $p 1$ or Der $p$ 2. The rate of cases missing slgE against both major allergens was higher among patients with negative nasal provocation test results than among patients with positive results (38\% vs 16\%).

${ }^{b}$ Concentrations and CAP classes are given as median and range. All remaining values are given as total number of patients and percentage for each group.

clinically silent sensitization. Despite having a higher total IgE serum level, patients without allergic symptoms had lower sIgE levels against the natural HDM extract (d1) and against the tested components Der $\mathrm{p} 1$ and Der $\mathrm{p} 2$. In order to take total IgE levels into account, the quotient of sIgE levels and the total $\mathrm{IgE}$ level in serum was calculated for each allergen component.

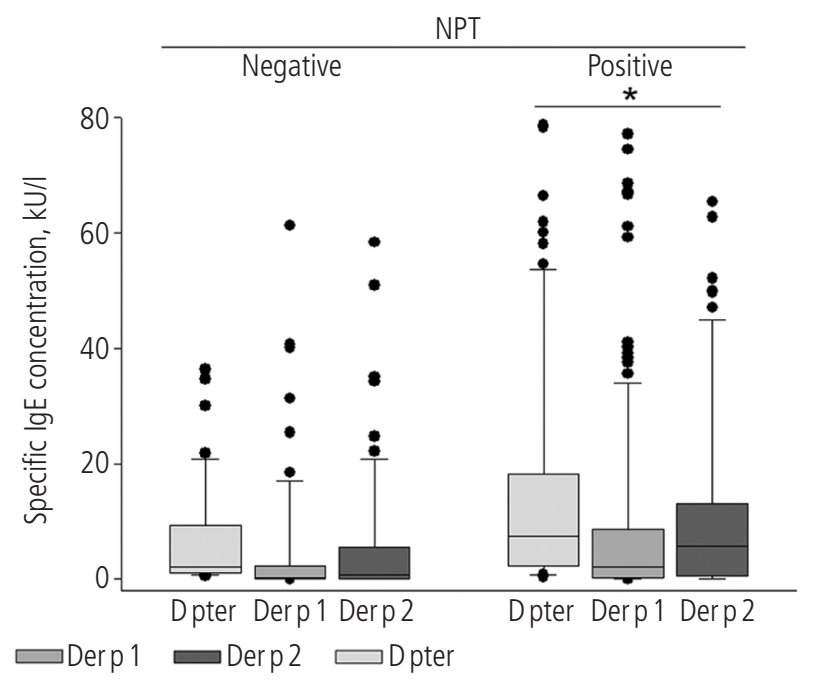

Figure 1. slgE titer against house dust mite extract (D pter), Der $p 1$ and Der $p 2$ in patients with positive NPT to Dermatophagoides pteronyssinus compared with patients with negative NPT. All measured slgE titers were significantly higher in patients with positive nasal challenge results than in patients with clinically silent sensitization $\left({ }^{*} P<.05\right)$. NPT indicates nasal provocation test.
As shown in Table 2 and Figure 1, the levels of sIgE against natural HDM extract $\mathrm{d} 1$, rDer $\mathrm{p} 1$, and rDer $\mathrm{p} 2$ were significantly higher in allergic patients than in persons with clinically silent sensitization. As many patients displayed sIgE either to Der $\mathrm{p} 1$ or Der $\mathrm{p} 2$, we summed the sIgE level against Der p 1 and Der p 2 in each group (Table 2). Comparing the sum of $\operatorname{sIgE}$ to Der $\mathrm{p} 1$ and to Der $\mathrm{p} 2$ between the groups improved the level of statistical significance.

As shown in Figure 2, the proportion of patients with HDM-induced rhinitis was higher among individuals with sIgE reactivity to both Der p 1 and Der p $2(98 / 120,82 \%)$ than

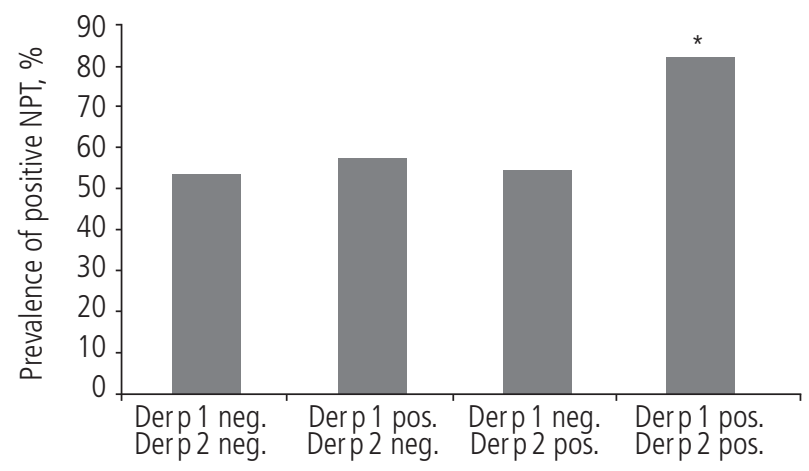

Figure 2. Prevalence of clinically relevant allergy to house dust mite in relation to positivity or negativity of slgE to Der $p 1$ and Der $p 2$. The proportion of house dust mite-allergic individuals was higher among patients with slgE reactivity against both house dust mite components than in patients reacting to only 1 component or none $\left({ }^{*} P<.001\right)$. NPT indicates nasal provocation test. 


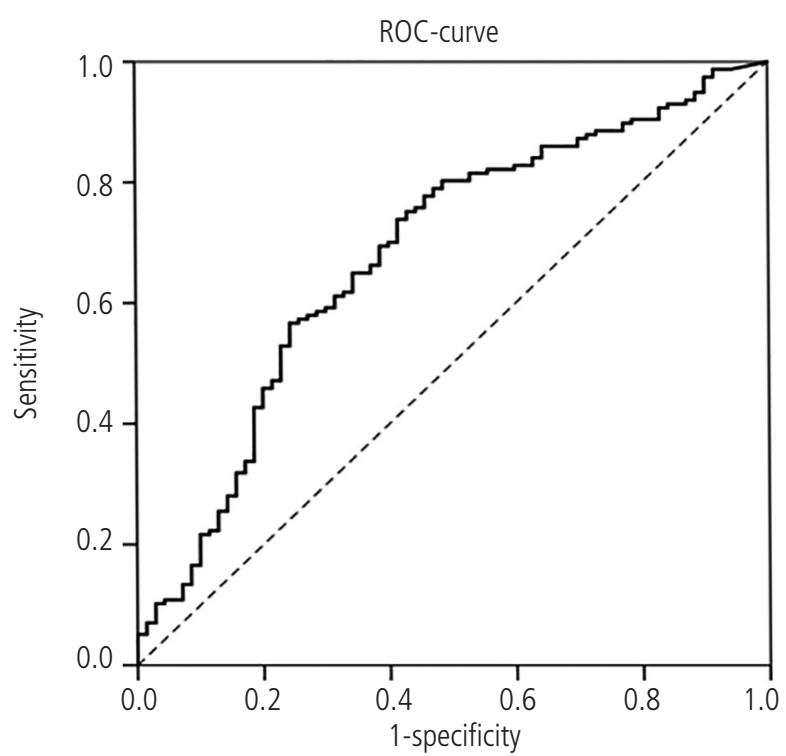

Figure 3. Receiver operating characteristic (ROC) curve of slgE testing (anti-Der p 1/total lgE + anti-Der p 2/total lgE) and results of the nasal provocation test: The ROC curve analysis reveals a positive correlation between slgE titer and the result of the nasal provocation test, albeit with low accuracy. NPT indicates nasal provocation test.

among those patients who reacted to only 1 allergen (Der $\mathrm{p} 1$ or Der p 2, 35/63, 56\%) or neither of them $(26 / 49,53 \%)$.

ROC analysis revealed low accuracy for SIgE against the HDM extract (AUC, 0.641; 95\%CI, 0.557-0.725), against Der p 1 (AUC, 0.652; 95\%CI, 0.573-0.73), and against Der p 2 (AUC, 0.654; 95\%CI, 0.578-0.73). Again, summing the levels of sIgE to Der $\mathrm{p} 1$ and to Der $\mathrm{p} 2$ improves the result slightly by increasing the AUC to 0.659 (95\% CI, 0.583-0.736).

As patients with clinically silent sensitization had a higher total IgE level in serum than allergic patients, we calculated the quotient of the sIgE levels and the total IgE levels before re-analyzing the ROC curves for each parameter. The AUC increased to 0.661 (95\% CI, 0.582-0.74) for total IgE-adjusted sIgE against the HDM extract, to 0.678 (95\% CI, 0.5990.756 ) against Der p 1, and to 0.671 (95\%CI, 0.596-0.745) against Der $\mathrm{p} 2$. Again, the sum of both $\mathrm{sIgE}$ to Der $\mathrm{p} 1$ and sIgE to Der $\mathrm{p} 2$, adjusted for total IgE level, showed the best correlation with the NPT result (AUC, 0.680; 95\%CI, 0.6030.757; Figure 3).

Earlier studies indicate that age might influence the results of in vivo and in vitro tests [19-21]. Therefore, we analyzed the ROC curves after excluding data from patients younger than 12 years and older than 60 years. However, adjustment for age did not lead to a relevant change in the above-mentioned results.

\section{Discussion}

The present study, which was based on real-life data, clearly demonstrates a significant correlation between allergenspecific IgE serum levels and NPT results in HDM-sensitized patients. However, in contrast to other studies $[15,16]$, the concordance between in vitro and in vivo measurements is not sufficiently strong to enable one method to be replaced by the other. A recent study by Comite et al [15] suggested a Der $\mathrm{p} 1$ threshold value of $5.5 \mathrm{kU} / \mathrm{L}$ for distinguishing between silent sensitization and symptomatic allergy in patients positive to Der $\mathrm{p} 1$, with a corresponding sensitivity of $94 \%$ and a specificity of $84 \%$. Applying this cutoff value to our Der p 1positive patients led to a sensitivity of $78 \%$ and a specificity of $55 \%$. In order to analyze and understand this discrepancy between our data and those from other studies, it is essential to perform a precise comparison of the methods used and populations studied among different publications.

To our knowledge, the population of the present study (232 patients) is the largest to date with respect to analysis of the correlation between in vivo and in vitro tests for HDM allergy in the era of component-resolved diagnostics. Most published studies using recombinant allergen components enrolled fewer than 100 patients $[15,16,19]$. However, according to Metz [22], a valid qualitative conclusion can be drawn from ROC curves for approximately 100 clinical cases.

Despite the large study population, our results should be interpreted with caution, as data were obtained during clinical routine and, therefore, do not reach the quality standards of prospective trials. For example, neither the doctors nor the patients were blinded to the SPT and serology results when performing the NPT. However, although the patients included do not represent the general population, the study population appears relatively representative of the population with allergic rhinitis: all patients with suspected allergic rhinitis were tested for sensitization to HDM, and, in a second step, patients with any indication of sensitization to HDM underwent sIgE measurements and NPT. This approach did not allow for exceptions, thus making selection bias less likely. Furthermore, all patients underwent NPT to distinguish between sensitization and allergy, even if the clinical history was suggestive of either the presence or the absence of allergic symptoms under exposure to HDM. Many other studies have the limitation that the clinical relevance of sensitization is not always proven by provocation tests, but only partially assumed based on data from the clinical history [10,15,23]. Rhinitis can by caused by many different factors. A recent review provides a detailed overview of the causes of nasal obstruction as a major symptom of rhinitis [24]. The quality and severity of symptoms are comparable in patients with negative and positive NPT, especially in patients sensitized to HDM [25]. Given that the clinical history is not suitable for evaluating the clinical relevance of sensitization to HDM, patients sensitized to HDM in our study underwent NPT. However, one potential methodological limitation is the various ages of patients ( 6 to 73 years). According to earlier studies [19-21], age affects skin testing and sIgE reactivity. Consequently, our results could be limited by the wide age range of the study population, although an age-adjusted subgroup analysis did not indicate any change in our results.

The reliability of NPT is still open to debate. However, we performed NPT according to current German guidelines [18], which are similar to Spanish guidelines [26]. In a very recent position paper on the standardization of nasal allergen challenges, the European Academy of Allergy and Clinical 
Immunology recommends a protocol that is very similar to the method used in the present study [27].

The patients' demographic and clinical features seem to confirm the representative character of our study population: the rate of clinical relevance of sensitization to HDM was $69 \%$ in the study population, which, according to Burbach et al [28], is typical for Germany.

The overall prevalence for self-reported asthma was $34 \%$. A meta-analysis of 13,558 HDM-sensitized patients from 16 countries revealed an overall prevalence for asthma of $21 \%$. However, the study populations analyzed were heterogeneous [29]. In a recent observational survey on 1589 patients with proven HDM allergy in France, approximately 42\% of patients with HDM-related allergic rhinitis had allergic asthma [30]. In our study population, only $30 \%$ of patients with allergic rhinitis due to D pteronyssinus also had asthma. This discrepancy might be due to the fact that the interaction between exposure to HDM allergens and symptoms is very complex in asthmatic patients and influenced by environmental and genetic factors [2].

Among patients without HDM-related allergic rhinitis, the prevalence of asthma was unexpectedly higher (43\%). Nevertheless, a negative NPT result to HDM does not imply the absence of other allergies as a potential eliciting factor for asthma: $47 \%$ of the asthmatic patients in the present study were polysensitized, thus making it difficult to determine the contribution of a specific allergen to airway inflammation [31].

Our demographic, clinical, and laboratory findings indicate that the study population was representative. Consequently, the immense discrepancy between the results of the present study and earlier publications cannot be explained only by the methodological limitations of our study. Comite et al [15] reported a remarkable AUC of 0.95 for Der $p 1$ that made it possible to distinguish between sensitization and allergy. The authors based their study on an artificial study population of 73 patients sensitized to Der $p 1$. The hypothesis that this study population is not representative is emphasized by the low rate of clinical relevance among the study group: only half of the study patients had allergic symptoms. However, according to Burbach et al [28], the rate of clinical relevance among HDM-sensitized patients in Italy is about $90 \%$. Another methodological reason for the discrepancy between our results and those reported in the literature could be the fact that the total serum IgE level was not taken into account in the other studies. For example, in the study by Minami et al [16], who reported a clear concordance between clinical relevance and sIgE measurements, total IgE values in sera of allergic patients were more than 3 -fold higher than in patients with clinically silent sensitization. One could debate that the correlation between sIgE measurements and clinical relevance would have been weaker than published, if this relevant difference in total IgE level had been taken into account. Another methodological difficulty affecting studies on the concordance of in vivo and in vitro testing for HDM allergy is the definition and subsequent exclusion of false-positive patients. We excluded 9 patients as false positives after their positive SPT result was followed by negative SIgE measurements against the natural HDM extract. Some studies report large numbers of patients with positive SPT results to HDM but no IgE reactivity to allergen components. In the study by Haxel et al [6], for example, 27 out of 50 patients with silent sensitization (54\%) had positive SPT and negative sIgE results [6]. As it remains unclear whether sIgE against the natural HDM extract was determined, falsepositive SPT results cannot be excluded.

Irrespective of the methodological differences and discrepancies regarding results between different publications on HDM allergy, all studies - including the present analysisclearly demonstrate that the risk of allergic symptoms increases with the level of sIgE against the natural HDM extract,

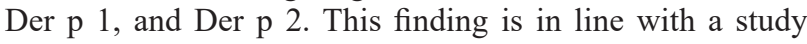
by Olivieri et al [32], who proved that $\operatorname{sgE}$ level was the most important predictor of allergen-related symptoms. The highest risk of having clinically relevant HDM sensitization was found in patients who reacted to both Der p 1 and Der $\mathrm{p} 2$. Vidal et al [33] found a similar association between simultaneous reactivity to Der $\mathrm{p} 1$ and Der $\mathrm{p} 2$ and asthma. When Der p 1 and Der p 2 were analyzed individually, both performed equally well with respect to the prevalence of clinically relevant sensitization. This result contrasts with those reported by Sylvestre et al [34], who had found higher titers of Der p 2 in patients with severe atopic asthma. However, this subgroup of patients was not present in our study.

Despite the reproducible observation that SIgE levels correlate with the prevalence of allergic symptoms, our data demonstrate that the statistical accuracy of sIgE against any tested allergen component, as well as natural HDM extract, is too low to distinguish between sensitization and allergy. This finding is in line with earlier investigations that determined sIgE only against the natural HDM extract $[25,35]$. There are several potential explanations why quantitative sIgE serology is not suitable for predicting the clinical relevance of sensitization to HDM. First, the allergic tissue reaction induced by an allergen depends not only on the level of sIgE, but also on the number and sensitivity of effector cells in the skin or the nasal mucosa. Second, skin or nasal sensitivity can be influenced by allergen-specific neutralizing IgG, which might inactivate allergic effector cells by competing with IgE. Third, the structure of IgE epitopes on an allergen can vary, as can the affinity of sIgE.

\section{Conclusion}

In contrast to data from recently published studies, our real-life data on 232 patients sensitized to HDM show that measuring SIgE against Der p 1, or Der p 2, or natural HDM extract is not suitable for predicting the clinical relevance of sensitization to HDM. According to our data, quantitative sIgE serology cannot replace NPT, which remains the gold-standard test for evaluating the clinical relevance of sensitization to HDM. We consider this an important message in times of growing interest in molecular-based allergy diagnostics. Current attempts by industry to reduce the testing portfolio endangers reliable diagnosis of allergic rhinitis, for which availability of NPT solutions is crucial.

\section{Funding}

The authors declare that no funding was received for the present study. 


\section{Conflicts of Interest}

The authors declare that they have no conflicts of interest.

\section{References}

1. Bauchau V, Durham SR. Prevalence and rate of diagnosis of allergic rhinitis in Europe. Eur Respir J. 2004;24:758-64.

2. Calderon MA, Linneberg A, Kleine-Tebbe J, De Blay F, Hernandez Fernandez de Rojas D, Virchow JC, et al. Respiratory allergy caused by house dust mites: What do we really know? J Allergy Clin Immunol. 2015;136:38-48.

3. Linneberg A, Henrik Nielsen N, Frolund L, Madsen F, Dirksen $A$, Jorgensen $T$. The link between allergic rhinitis and allergic asthma: A prospective population-based study. The Copenhagen Allergy Study. Allergy. 2002;57:1048-52.

4. Sporik R, Holgate ST, Platts-Mills TA, Cogswell JJ. Exposure to house-dust mite allergen (Der p 1) and the development of asthma in childhood. A prospective study. N Engl J Med. 1990:323:502-7.

5. Murray AB, Milner RA. The accuracy of features in the clinical history for predicting atopic sensitization to airborne allergens in children. J Allergy Clin Immunol. 1995;96:588-96.

6. Haxel BR, Huppertz T, Boessert P, Bast F, Fruth K. Correlation of skin test results and specific immunoglobulin e blood levels with nasal provocation testing for house-dust mite allergies. Am J Rhinol Allergy. 2016;30:60-4.

7. Riechelmann H, Bachert C, Goldschmidt O, Hauswald B, Klimek L, Schlenter WW, et al. [Application of the nasal provocation test on diseases of the upper airways. Position paper of the German Society for Allergology and Clinical Immunology (ENT section) in cooperation with the Working Team for Clinical Immunology]. Laryngorhinootologie. 2003;82:183-8.

8. Gosepath J, Amedee RG, Mann WJ. Nasal provocation testing as an international standard for evaluation of allergic and nonallergic rhinitis. Laryngoscope. 2005;115:512-6.

9. Sampson HA, Ho DG. Relationship between food-specific $\lg$ E concentrations and the risk of positive food challenges in children and adolescents. J Allergy Clin Immunol. 1997; 100:444-51

10. Ciprandi G, Comite P, Ferrero F, Minale P, Voltolini S, Bignardi $D$, et al. Can serum white birch (Betula verrucosa) pollen antigen (Bet v 1) immunoglobulin E measurement distinguish between sensitization and allergy? Int Forum Allergy Rhinol. 2015;5:1151-5.

11. Klimek L, Hammerbacher AS, Hellings PW, Fokkens WJ, Hoffmann HJ, Muraro A, et al. The influence of European legislation on the use of diagnostic test allergens for nasal allergen provocation in routine care of patients with allergic rhinitis. Rhinology. 2015;53:260-9.

12. Klimek L, Hoffmann HJ, Renz H, Demoly P, Werfel T, Matricardi $\mathrm{PM}$, et al. Diagnostic test allergens used for in vivo diagnosis of allergic diseases are at risk: A European Perspective. Allergy. 2015;70:1329-31.

13. Bousquet J, Lebel B, Dhivert $H$, Bataille $Y$, Martinot B, Michel FB. Nasal challenge with pollen grains, skin-prick tests and specific IgE in patients with grass pollen allergy. Clin Allergy. 1987; 17:529-36.
14. Rasanen L, Kuusisto P, Penttila M, Nieminen M, Savolainen J, Lehto M. Comparison of immunologic tests in the diagnosis of occupational asthma and rhinitis. Allergy. 1994;49:342-7.

15. Comite P, Minale P, Ferrero F, Mussap M, Ciprandi G. Der $p$ $1 \mathrm{lgE}$ measurement for distinguishing between sensitization and allergy. Immunol Lett. 2015;166:145-6.

16. Minami T, Fukutomi Y, Lidholm J, Yasueda H, Saito A, Sekiya K, et al. IgE Abs to Der $p 1$ and Der $p 2$ as diagnostic markers of house dust mite allergy as defined by a bronchoprovocation test. Allergol Int. 2015;64:90-5.

17. Bernstein IL, Storms WW. Practice parameters for allergy diagnostic testing. Joint Task Force on Practice Parameters for the Diagnosis and Treatment of Asthma. The American Academy of Allergy, Asthma and Immunology and the American College of Allergy, Asthma and Immunology. Ann Allergy Asthma Immunol. 1995;75:543-625.

18. Cazan D, Hackenberg B, Pfaar O, Klimek L. Die nasale Provokationstestung mit Allergenen. Methoden der klinischen Anwendung. Allergo Journal. 2013;22:4.

19. King MJ, Tamulis T, Lockey RF. Prick puncture skin tests and serum specific lgE as predictors of nasal challenge response to Dermatophagoides pteronyssinus in older adults. Ann Allergy Asthma Immunol. 2008;101:12-7.

20. de Vos G, Nazari R, Ferastraoaru D, Parikh P, Geliebter R, Pichardo $Y$, et al. Discordance between aeroallergen specific serum IgE and skin testing in children younger than 4 years. Ann Allergy Asthma Immunol. 2013;110:438-43.

21. Simola $M$, Holopainene $E$, Malmberg $H$. Changes in skin and nasal sensitivity to allergens and the course of rhinitis; a long-term follow-up study. Ann Allergy Asthma Immunol. 1999;82:152-6.

22. Metz CE. Basic principles of ROC analysis. Semin Nucl Med. 1978;8:283-98.

23. Comite P, Ferrero F, Mussap M, Ciprandi G. Par j 2 lgE measurement for distinguishing between sensitization and allergy. Allergol Int. 2015;64:384-5.

24. Valero A, Navarro AM, Del Cuvillo A, Alobid I, Benito JR, Colas C, et al. Position paper on nasal obstruction: evaluation and treatment. J Investig Allergol Clin Immunol. 2018;28:67-90.

25. Riechelmann $H$, Mewes $T$, Weschta M, Gropper G. Nasal allergen provocation with Dermatophagoides pteronyssinus in patients with chronic rhinitis referred to a rhinologic surgical center. Ann Allergy Asthma Immunol. 2002;88:624-31.

26. Dordal MT, Lluch-Bernal M, Sanchez MC, Rondon C, Navarro A, Montoro J, et al. Allergen-specific nasal provocation testing: Review by the rhinoconjunctivitis committee of the Spanish Society of Allergy and Clinical Immunology. J Investig Allergol Clin Immunol. 2011;21:1-12.

27. Augé J, Vent J, Agache I, Airaksinen L, Campo Mozo P, Chaker $A$, et al. EAACI Position paper on the standardization of nasal allergen challenges. Allergy. 2018;73:1597-1608.

28. Burbach GJ, Heinzerling LM, Edenharter G, Bachert C, Bindslev-Jensen C, Bonini S, et al. Ga(2)len skin test study ii: Clinical relevance of inhalant allergen sensitizations in Europe. Allergy. 2009;64:1507-15.

29. Sunyer J, Jarvis D, Pekkanen J, Chinn S, Janson C, Leynaert B, et al. Geographic variations in the effect of atopy on asthma 
in the European community respiratory health study. J Allergy Clin Immunol. 2004;114:1033-9.

30. Demoly P, Broue-Chabbert A, Wessel F, Chartier A. Severity and disease control before house dust mite immunotherapy initiation: ANTARES a French observational survey. Allergy Asthma Clin Immunol. 2016;12:13.

31. Løvik M, Gaarder, P, Mehl, R. The house-dust mite: Its biology and role in allergy. Proceedings of an International scientific workshop. Oslo, Norway, 4-7 september 1997. Allergy. 1998:53:1-135

32. Olivieri $M$, Heinrich J, Schlunssen $V$, Anto JM, Forsberg $B$, Janson $C$, et al. The risk of respiratory symptoms on allergen exposure increases with increasing specific lgE levels. Allergy. 2016;71:859-68.

33. Vidal C, Lojo S, Juangorena M, Gonzalez-Quintela A. Association between asthma and sensitization to allergens of Dermatophagoides pteronyssinus. J Investig Allergol Clin Immunol. 2016;26:304-9.

34. Sylvestre L, Jegu J, Metz-Favre C, Barnig C, Qi S, de Blay F. Component-based allergen-microarray: Der $p 2$ and Der $f 2$ dust mite sensitization is more common in patients with severe asthma. J Investig Allergol Clin Immunol. 2016;26:141-3.

35. Niggemann B, Kleinau I, Schou C, Hansen GN, Wahn U. Discrepancies between in vitro and in vivo tests for house dust mite allergy: In domestic exposure a better predictor than sensitization? Clin Exp Allergy. 1994;24:946-8.

Manuscript received March 6, 2018; accepted for publication July 30, 2018.

\section{- Donata Gellrich}

Department of Otorhinolaryngology

Head and Neck Surgery

Ludwig-Maximilians-University Hospital Munich

Marchioninistr. 15, D - 81377 Munich (Germany)

E-mail: Donata.Gellrich@med.uni-muenchen.de 